Article

\title{
Heat-Dissipation Performance of Nanocomposite Phase-Change Materials in a Twin-Heat-Source System
}

\author{
Yanxin $\mathrm{Li}^{1}{ }^{1}$, Jin Wang ${ }^{1}$, Li Yang ${ }^{1}$ and Bengt Sundén ${ }^{2, *} \mathbb{C}$ \\ 1 School of Energy and Environmental Engineering, Hebei University of Technology, Tianjin 300401, China; \\ liyanxin2162862@163.com (Y.L.); wjwcn00@163.com (J.W.); dyli1018@163.com (L.Y.) \\ 2 Department of Energy Sciences, Division of Heat Transfer, Lund University, SE-22100 Lund, Sweden \\ * Correspondence: bengt.sunden@energy.lth.se (B.S.)
}

Received: 28 August 2020; Accepted: 3 October 2020; Published: 7 October 2020

check for updates

\begin{abstract}
In this paper, pure paraffin was mixed with $\mathrm{CuO}$ (high thermal conductivity) and Span-80 (as a dispersant). The $\mathrm{CuO} /$ paraffin nanocomposite phase-change materials (PCMs) were synthesized with mass fractions of $0.3 \%, 0.6 \%$, and $1.2 \%$, by a two-step method. Heat-transfer characteristics of the heat-pipe-PCMs module and effects of fan power and heating power on the performance of the cooling module in a twin-heat-source system were studied. For two heat sources under $10 \mathrm{~W}-10$ $\mathrm{W}$ (heat source 1 with a power of $10 \mathrm{~W}$ and heat source 2 with a power of $10 \mathrm{~W}$ ), the paraffin wax decreases the evaporator temperature by $14.4 \%$, compared with cases without PCMs.
\end{abstract}

Keywords: heat pipe; nanocomposite; twin heat source; electronic cooling

\section{Introduction}

Recently, phase-change materials (PCMs) have been widely used in electronics cooling due to their high heat storage capacity during phase-change processes [1]. Compared with the sensible heat storage, the latent heat storage provides higher energy density and more stable operating temperature. Paraffin wax is commonly taken as an organic phase-change material due to its advantages of stable chemical performance, high latent heat, low cost, and no supercooling [2]. However, the paraffin wax has a low thermal conductivity, which limits its application in various fields. This behavior can be improved by mixing multi-walled carbon nanotubes (CNTs), carbon nanofibers, and graphene nanoplatelets (GNPs) into the PCMs [3]. In addition, Wu et al. [4] found that paraffin with 3\% CNTs showed $30.3 \%$ and $28.5 \%$ increases in thermal conductivities of the solid and liquid phases, respectively. Babapoord and Karimi [5] found that thermal conductivity of $6 \mathrm{wt} . \% \mathrm{Al}_{2} \mathrm{O}_{3}$ nanocomposite PCMs increased by $141.2 \%$, compared to paraffin wax. Arshad et al. [6] found that hybrid nano-enhanced PCMs had the highest thermal conductivity enhancement of $96 \%$ compared to pure paraffin. Li et al. [7] numerically and experimentally investigated the thermal behavior of microencapsulated PCMs saturated in a metal foam, and they found that it effectively improved the thermal conductivity of the PCMs for passive thermal management.

For the electronics cooling, Ren et al. [8] optimized pin-fin cascade microencapsulated PCMs/expanded graphite composite material, and the composite PCMs were used for thermal performance improvement of electronic equipment. Ling et al. [9] proposed an effective cooling method for electronic equipment by integrating PCMs with a three-dimensional oscillating heat pipe, and they found that the best performance was observed with a filling ratio of $34 \%-44 \%$. Yang et al. [10] developed a PCM-based finned heat pipe radiator which prolonged the working duration 1.4-2.4 times compared to that of low melting point metal $\left(\mathrm{Bi}_{31.6} \mathrm{In}_{48.8} \mathrm{Sn}_{19.6}\right)$. Krishna et al. [11] investigated the 
effect of different fan powers and heating powers on the temperature of the evaporator in a PCM cooling module. Yu et al. [12] studied heat dissipation of heat pipes with the PCM cooling in a multiple-heat-source system. It was found that phase-change material RT35 maintained temperature variations of the evaporator at a lower temperature.

In this paper, nano-CuO/paraffin composites are used to investigate heat-transfer characteristics of the heat pipe/PCM nanocomposite coupling module in a twin-heat-source system. For the finned heat pipe assisted with $\mathrm{PCMs}$, effects of nanoparticle $\mathrm{CuO}$ on thermal properties of the paraffin have not been fully discussed in published references. A comparison of heat pipes with and without paraffin is conducted to investigate heat-transfer characteristics first, and then the effect of the nanoparticle addition is investigated by changing the mass fraction of the $\mathrm{CuO}$ nanoparticles. Finally, the effect of the cooling module performance is analyzed at various fan powers and heating powers.

\section{Experimental Preparation}

\subsection{Experimental Materials and Instruments}

Paraffin wax (Kmart Chemical Technology Company, Tianjin, China) has a melting temperature of $35 \sim 37^{\circ} \mathrm{C}$, and its thermal conductivity is $0.2 \mathrm{~W} / \mathrm{m} \cdot \mathrm{K}$. Latent heat and specific heat of paraffin wax are $172 \mathrm{~kJ} / \mathrm{kg}$ and $2.1 \mathrm{~kJ} / \mathrm{kg} \cdot \mathrm{K}$, respectively. The nanoparticle $\mathrm{CuO}$ (Beijing Dekedao Gold Technology Company, Beijing, China) with an average particle size of $30 \mathrm{~nm}$ has a specific surface area of $13.1 \mathrm{~m}^{2} / \mathrm{g}$, and its thermal conductivity is $37 \mathrm{~W} / \mathrm{m} \cdot \mathrm{K}$. The Span-80 (Kmart Chemical Technology Company, Tianjin, China) is made of sorbitan fatty acid ester. Accuracies of instruments are listed in Table 1.

Table 1. Accuracies of instruments.

\begin{tabular}{cccc}
\hline Equipment & Model & Instrument Range & Accuracy \\
\hline Ultrasonic oscillator & SK1200H-J & - & - \\
Electronic balance & FA2004B & $0 \sim 200 \mathrm{~g}$ & $\pm 0.0001 \mathrm{~g}$ \\
Thermostatic water bath & $\mathrm{HH}-1$ & $0 \sim 99.9{ }^{\circ} \mathrm{C}$ & $\pm 1{ }^{\circ} \mathrm{C}$ \\
Agilent data collector & $34972 \mathrm{~A}$ & - & $\pm 0.001{ }^{\circ} \mathrm{C}$ \\
Infrared camera & TESTO $885-2$ & $-20 \sim 1200{ }^{\circ} \mathrm{C}$ & $\pm 2{ }^{\circ} \mathrm{C}$ \\
\hline
\end{tabular}

\subsection{Preparation of Composite PCMs}

With paraffin wax as a base material, nano-CuO/paraffin composite PCMs are prepared by a two-step method. Then, $40 \mathrm{~g}$ of paraffin is accurately weighted by using an electronic scale (Shanghai Precision Instrument Co., Ltd., Shanghai, China) and put into a water bath (Changzhou Guohua Electric Co., Ltd., Changzhou, China). After the paraffin melts, different mass fractions of nanoparticles are mixed into the paraffin. Dispersant Span- 80 and nanoparticles are mixed at a ratio of 1:1, $40 \mathrm{~min}$ ultrasonic oscillation at $40 \mathrm{kHz}$ frequency and $70{ }^{\circ} \mathrm{C}$ were used in the preparation of the stable nanocomposite PCMs. Figure 1 shows nanoparticle images obtained by a scanning electron microscopy (SEM) and the preparation procedure of nanocomposite PCMs. 


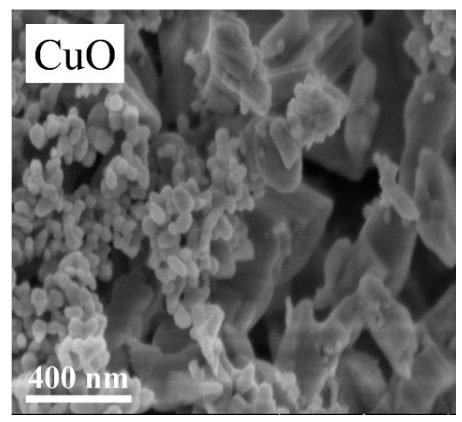

(a)

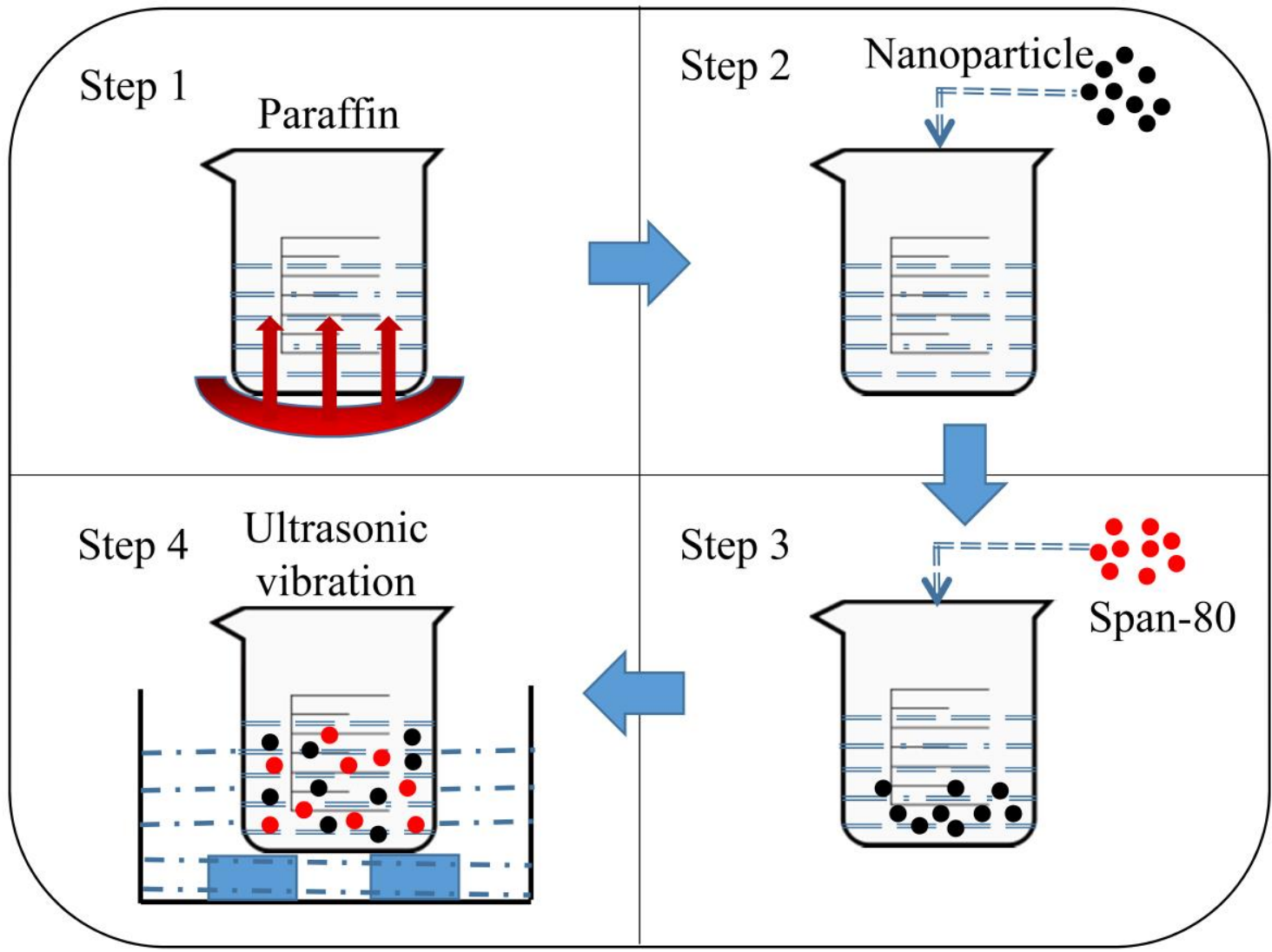

(b)

Figure 1. SEM of the nanoparticle $\mathrm{CuO}$ and scheme for composite preparation: (a) $\mathrm{CuO}$ nanoparticles and (b) preparation procedure of nanocomposite phase-change materials (PCMs).

\subsection{Experimental System}

Figure 2 shows the system diagram of the device used to investigate the cooling performance of the heat-pipe-PCM module in a twin-heat-source system. The experimental setup consists of a copper heat pipe, a heat sink fin, a PCM tank, a cooling fan, two block heaters, two DC power supplies, a computer, and a data collector (Agilent Technologies Inc., California, United States). T-type thermocouples with an accuracy of $\pm 0.5^{\circ} \mathrm{C}$ were used to measure temperature values of the pipe and PCMs at different locations. The flat heat pipe made of copper has a length of $310 \mathrm{~mm}$, a width of $11 \mathrm{~mm}$, and a height of $2.7 \mathrm{~mm}$. The thickness of the copper wall is $0.5 \mathrm{~mm}$. The cooling module is divided into three parts, i.e., the evaporation end (with a length of $100 \mathrm{~mm}$ ), the adiabatic end (with a length of $100 \mathrm{~mm}$ ), and the condensation end (with a length of $100 \mathrm{~mm}$ ). The heat in the experimental system is supplied to the evaporator end of the cooling module. A portion of the heat is absorbed by the PCMs filled in the PCM 
tank with a volume of $50 \mathrm{~mL}$. The heat sink is connected to the heat pipe, using thermal conductive silica gel, and the total cooling area of the heat sink is $0.0112 \mathrm{~m}^{2}$.

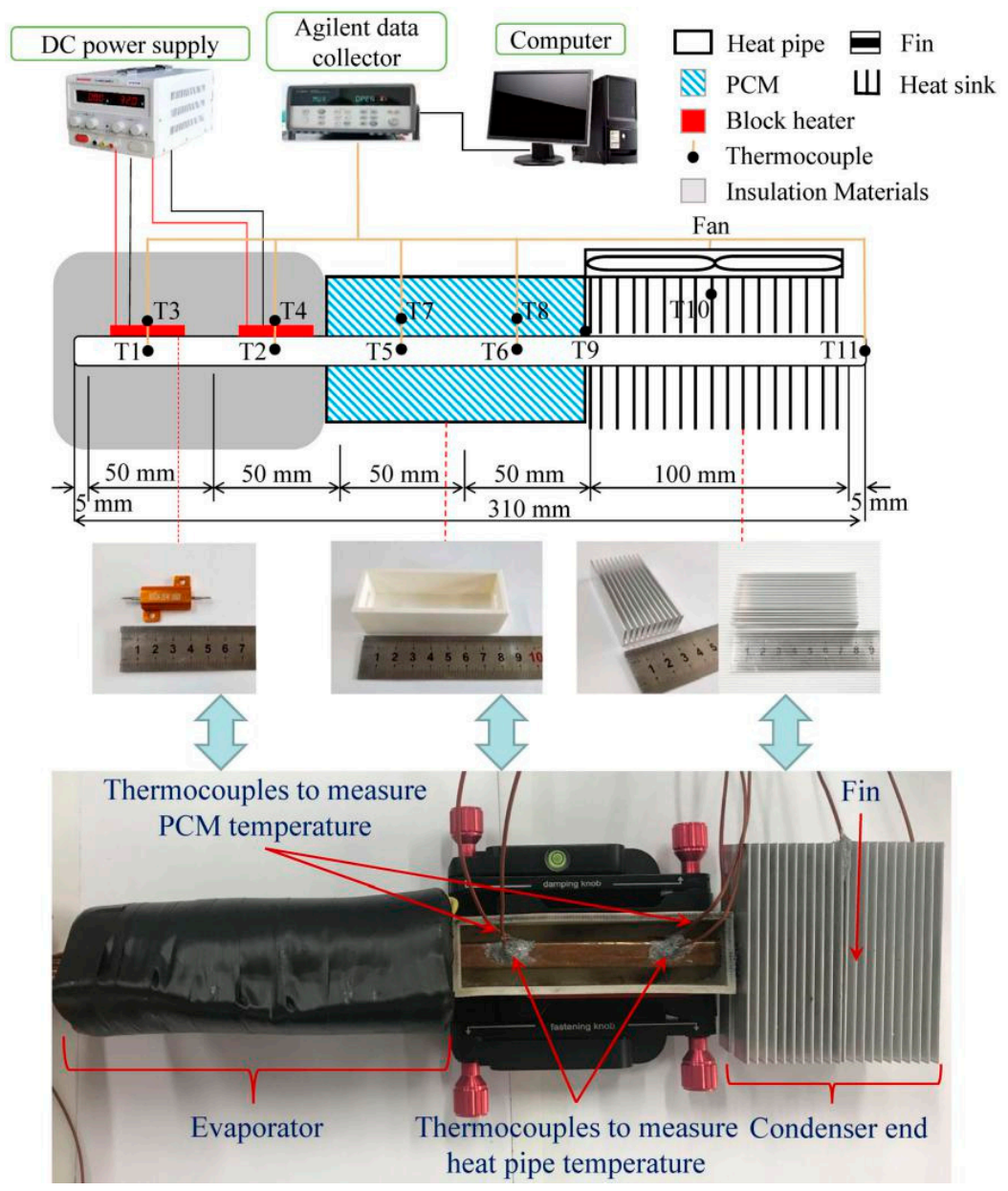

Figure 2. Photos of the testing components and experimental system.

\subsection{Experimental Uncertainty Analysis}

In order to provide a stable heat flow for the heat-pipe evaporator, an adjustable DC power supply is used. The stored thermal energy in the PCM is estimated as follows:

$$
Q=m C p(T e-T i)
$$

where $T_{i}$ and $T_{e}$ are the initial and terminal temperatures of the PCM during the heating and cooling processes, respectively, and the corresponding values are calculated as follows:

$$
\begin{aligned}
& T i=\frac{1}{2} \sum_{n=7}^{8} T n, i, \\
& T e=\frac{1}{2} \sum_{n=7}^{8} T n, e,
\end{aligned}
$$

The uncertainty of the PCM energy storage is calculated as follows:

$$
\frac{\Delta Q}{Q}=\sqrt{\left(\frac{\Delta m}{m}\right)^{2}+\left(\frac{\Delta(\Delta T)}{\Delta T}\right)^{2}},
$$


Based on uncertainty analyses of the Agilent data collector and thermocouple instrument tests, the accuracy of the T-type thermocouple is $\pm 0.5^{\circ} \mathrm{C}$. The accuracies of the current and voltage from the DC power supply are $\pm 0.1 \mathrm{~V}$ and $\pm 0.1 \mathrm{~A}$, respectively. For the independent variables $u, v$, and $w$, the error $\sigma y$ can be calculated according to the law of the error propagation, as shown in Equation (5) [13]. The analysis of the present experimental uncertainty is shown in Table 2.

$$
\sigma y=\left[\left(\frac{\partial f}{\partial u}\right)^{2} \sigma_{u}^{2}+\left(\frac{\partial f}{\partial v}\right)^{2} \sigma_{v}^{2}+\ldots+\left(\frac{\partial f}{\partial w}\right)^{2} \sigma_{w}^{2}\right]^{1 / 2},
$$

Table 2. Experimental uncertainties.

\begin{tabular}{cc}
\hline Variable & Maximum Uncertainty \\
\hline Heat input $(\mathrm{W})$ & $\pm 1.5 \%$ \\
Heat output $(\mathrm{W})$ & $\pm 3.1 \%$ \\
Thermocouple measuring temperature & $\pm 1 \%$ \\
PCM heat storage & $\pm 1.7 \%$ \\
\hline
\end{tabular}

\section{Results and Discussion}

\subsection{Effect of PCMs on the Cooling Performance}

The temperature change of the evaporator end is investigated to analyze the heat-transfer intensity of the heat-pipe-PCM module in the twin-heat-source system. The evaporator temperature is calculated as the average temperature of the heat sources 1 and 2 (measured by thermocouples). Figure 3 shows variations of the evaporator temperature under different heat-source powers, using various PCMs with the same volume of $50 \mathrm{~mL}$. When the heat sources 1 and 2 have the same power of $5 \mathrm{~W}$, the evaporator temperature for the case without PCMs (W/O PCM) has the highest value of $47.1^{\circ} \mathrm{C}$, as compared to other cases. It is found that addition of paraffin wax into the traditional heat pipe results in a temperature reduction of $7.6 \%$. When the heat sources 1 and 2 have the same power of $10 \mathrm{~W}$, it is found that, in the case of a high heat source, the application of paraffin wax as energy storage materials reduces the temperature of the evaporator by $14.4 \%$, compared to the case W/O PCM. This is because, for the case with a high heat source, more paraffin wax is melted and more heat is stored in the form of the latent heat.

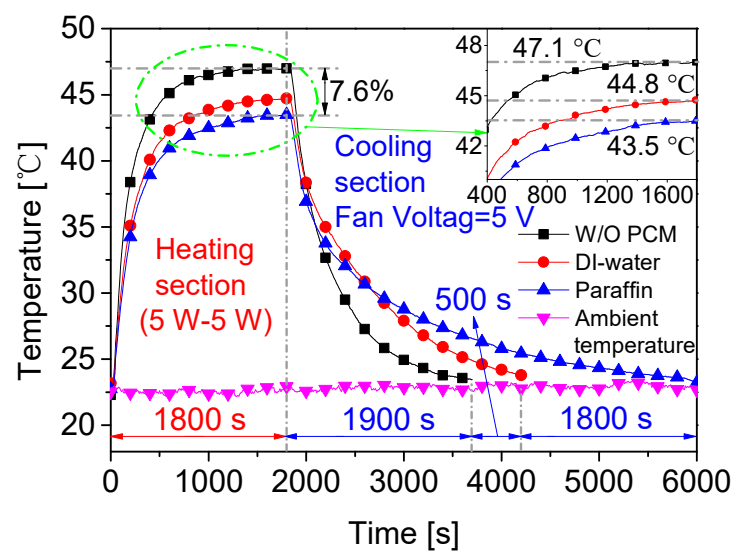

(a)

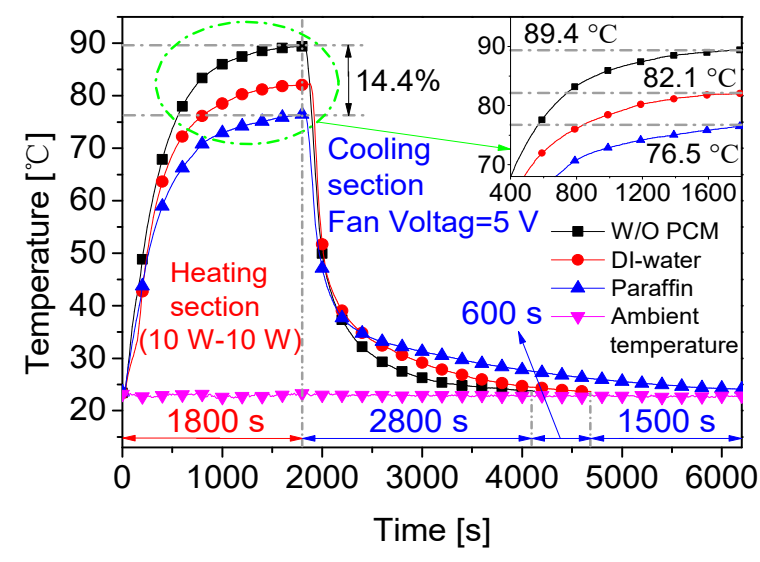

(b)

Figure 3. Temperature variations under different heating powers (heat source 1 power-heat source 2 power): (a) $5 \mathrm{~W}-5 \mathrm{~W}$ and (b) $10 \mathrm{~W}-10 \mathrm{~W}$. 


\subsection{Effect of Nanoparticle Concentration on the Performance of PCMs}

Paraffin is mixed with the nanoparticle $\mathrm{CuO}$ to improve the heat-transfer performance of the base material. As shown in Figure 4a, it is found that using 1.2\% CuO/paraffin as the phase-change energy-storage material has the best cooling effectiveness, and the evaporator temperature is reduced by $2.3 \%$ compared with the case with paraffin wax. For the heat sources 1 and 2 under the same power of $10 \mathrm{~W}$, the evaporator temperature of the heat pipe with $1.2 \% \mathrm{CuO} /$ paraffin is $12.5 \%$ lower than that with the pure paraffin, as shown in Figure $4 \mathrm{~b}$. It is found that the addition of the nanoparticle $\mathrm{CuO}$ improves the heat-transfer characteristics of the heat pipe.

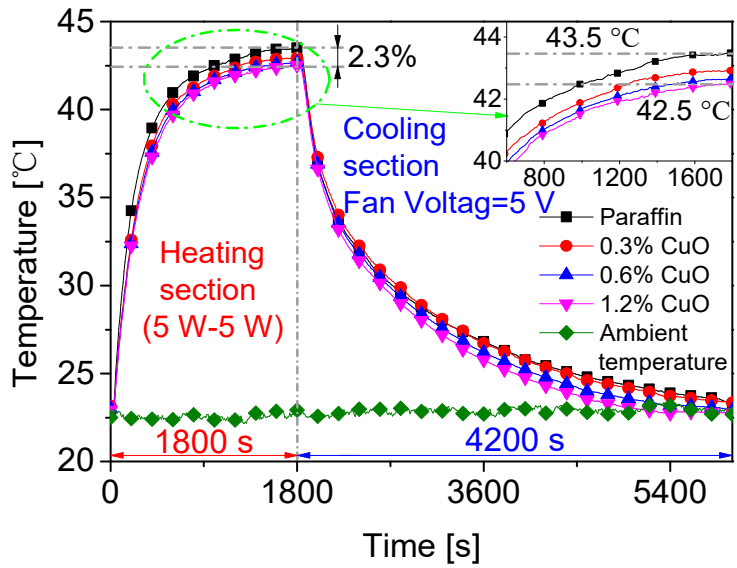

(a)

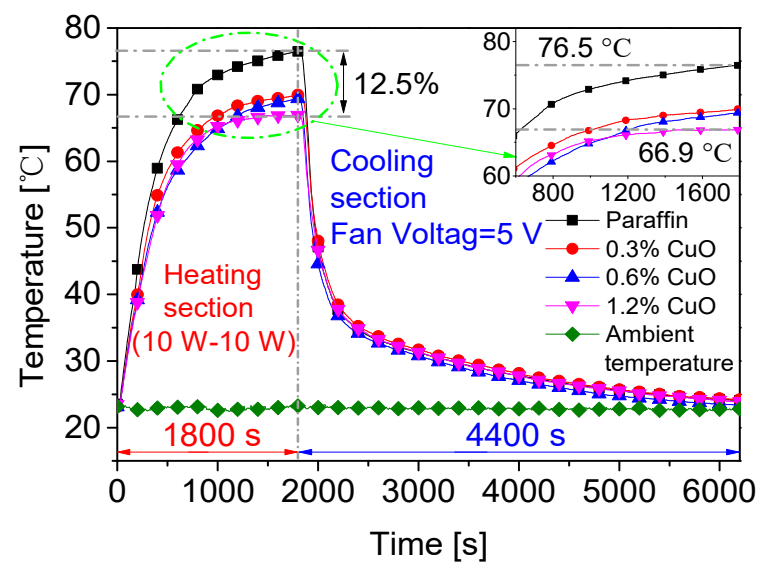

(b)

Figure 4. Temperature variations on the evaporator with phase-change materials at the heating power of (a) $5 \mathrm{~W}-5 \mathrm{~W}$ and (b) $10 \mathrm{~W}-10 \mathrm{~W}$.

\subsection{Analysis of Infrared Temperature Field}

During the charging and discharging processes, when the heating power changes in an electronic component, the heat will be stored in the PCMs first and then released slowly. To simulate the same actual situation, the heat source 1 has alternate powers of 5 and $10 \mathrm{~W}$ every $5 \mathrm{~min}$, as listed in Table 3 .

Table 3. Variable powers at different stages.

\begin{tabular}{cccc}
\hline Heating Stage & Heat-Source 1 Power & Heat-Source 2 Power & Time \\
\hline Heating stage 1 & $5 \mathrm{~W}$ & $10 \mathrm{~W}$ & $5 \mathrm{~min}$ \\
Heating stage 2 & $10 \mathrm{~W}$ & $10 \mathrm{~W}$ & $5 \mathrm{~min}$ \\
Heating stage 3 & $5 \mathrm{~W}$ & $10 \mathrm{~W}$ & $5 \mathrm{~min}$ \\
Heating stage 4 & $10 \mathrm{~W}$ & $10 \mathrm{~W}$ & $5 \mathrm{~min}$ \\
Heating stage 5 & $5 \mathrm{~W}$ & $10 \mathrm{~W}$ & $5 \mathrm{~min}$ \\
Heating stage 6 & $10 \mathrm{~W}$ & $10 \mathrm{~W}$ & $5 \mathrm{~min}$ \\
Heating stage 7 & $5 \mathrm{~W}$ & $10 \mathrm{~W}$ & $5 \mathrm{~min}$ \\
\hline
\end{tabular}

During different heating stages at fan voltages of 5 and $10 \mathrm{~V}$, Figure 5 shows the temperature distributions of the pure paraffin and $1.2 \% \mathrm{CuO} /$ paraffin composites, using an infrared thermal imager (Shenzhen Meikeyi Technology Co., Ltd., Shenzhen, China). It is observed that, during 15 min heating, the temperature distribution of the $1.2 \% \mathrm{CuO}$ /paraffin composites is somewhat different from that of pure paraffin. When the evaporator section is heated for $25 \mathrm{~min}$, a portion of the pure paraffin at $5 \mathrm{~V}$ fan voltage reaches above $40^{\circ} \mathrm{C}$, whereas all the pure paraffin has a temperature below $40^{\circ} \mathrm{C}$ at $10 \mathrm{~V}$ fan voltage. This result shows that the pure paraffin under $10 \mathrm{~V}$ fan voltage has a lower surface 
temperature field than that under $5 \mathrm{~V}$ fan voltage. In addition, during the $35 \mathrm{~min}$ heating process, it is easily found that the temperature distribution of the $1.2 \% \mathrm{CuO} /$ paraffin composites is significantly higher than that of pure paraffin. Under $5 \mathrm{~V}$ fan voltage, the maximum temperature difference between $1.2 \% \mathrm{CuO} /$ paraffin composites and pure paraffin at the same position is $3.3^{\circ} \mathrm{C}$. The results show that, compared with pure paraffin, the addition of the $1.2 \% \mathrm{CuO}$ nanoparticles can effectively improve the heat dissipation at the evaporator. When the fan runs at low power, more paraffin wax will melt completely. This result indicates that the latent heat of PCMs can be fully utilized to lower the temperature of the evaporator.

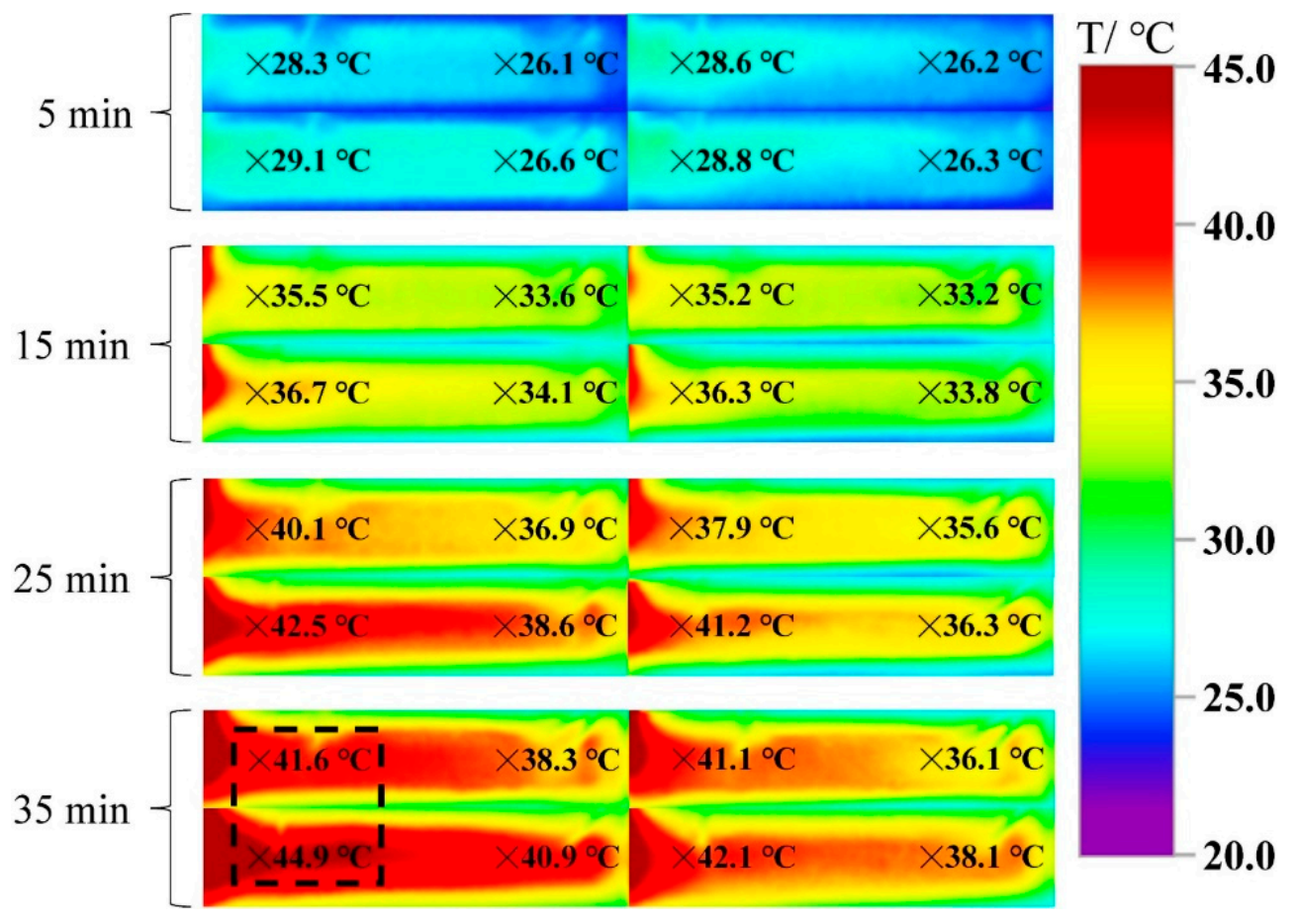

Figure 5. Temperature values on the adiabatic sections covered with the pure paraffin (up) and $\mathrm{CuO} /$ paraffin (down) under fan voltages $5 \mathrm{~V}$ (left) and $10 \mathrm{~V}$ (right), using an infrared thermal imager.

\section{Conclusions}

In a two-heat-source system, under a constant heating power, paraffin wax can effectively reduce the temperature of the evaporator. It is found that, when the power of the heat sources 1 and 2 is $10 \mathrm{~W}$, paraffin wax used as energy storage materials reduces the temperature of the evaporator by $14.4 \%$, compared with the case without paraffin wax.

Because $\mathrm{CuO} /$ paraffin nanocomposites can store more heat from the heat sources to avoid affecting the normal operation of the cooling module, the $\mathrm{CuO} /$ paraffin nanocomposites are used to weaken temperature fluctuations on the heat sources in this research. When the heating power of the heat sources 1 and 2 is $10 \mathrm{~W}$, the evaporator temperature of the heat pipe with $1.2 \% \mathrm{CuO} /$ paraffin is $12.5 \%$ lower than that with the pure paraffin.

Author Contributions: Methodology, Y.L.; formal analysis, Y.L. and J.W.; investigation, Y.L. and J.W.; writing-original draft preparation, Y.L. and J.W.; writing-review and editing, J.W. and B.S.; funding acquisition, J.W. and L.Y. All authors have read and agreed to the published version of the manuscript.

Funding: This work is supported by the National Natural Science Foundation of China (grant number 51876161) and the Project of Innovation Ability Training for Postgraduate Students of Education Department of Hebei Province (grant number CXZZSS2019012).

Conflicts of Interest: The authors declare no conflict of interest. 


\section{References}

1. Wang, Q.C.; Rao, Z.H.; Huo, Y.T.; Wang, S.F. Thermal performance of phase change material/oscillating heat pipe-based battery thermal management system. Int. J. Therm. Sci. 2016, 102, 9-16. [CrossRef]

2. Bose, P.; Amirtham, V.A. A review on thermal conductivity enhancement of paraffin wax as latent heat energy storage material. Renew. Sustain. Energy Rev. 2016, 65, 81-100. [CrossRef]

3. Fan, L.W.; Fang, X.; Wang, X.; Zeng, Y.; Xiao, Y.Q.; Yu, Z.T.; Xu, X.; Hu, Y.C.; Cen, K.F. Effects of various carbon nanofillers on the thermal conductivity and energy storage properties of paraffin-based nanocomposite phase change materials. Appl. Energy 2013, 110, 163-172. [CrossRef]

4. Wu, X.H.; Wang, C.X.; Wang, Y.L.; Zhu, Y.J. Experimental study of thermo-physical properties and application of paraffin-carbon nanotubes composite phase change materials. Int. J. Heat Mass Transf. 2019, 140, 671-677. [CrossRef]

5. Babapoor, A.; Karimi, G. Thermal properties measurement and heat storage analysis of paraffin nanoparticles composites phase change material: Comparison and optimization. Appl. Therm. Eng. 2015, 90, 945-951. [CrossRef]

6. Arshad, A.; Jabbal, M.; Yan, Y.Y. Preparation and characteristics evaluation of mono and hybrid nanoenhanced phase change materials (NePCMs) for thermal management of microelectronics. Energy Convers. Manag. 2020, 205, 112444. [CrossRef]

7. Li, W.Q.; Wan, H.; Jing, T.T.; Li, Y.B.; Liu, P.J.; He, G.Q.; Qin, F. Microencapsulated phase change material (MEPCM) saturated in metal foam as an efficient hybrid PCM for passive thermal management: A numerical and experimental study. Appl. Therm. Eng. 2019, 146, 413-421. [CrossRef]

8. Ren, Q.L.; Guo, P.H.; Zhu, J.J. Thermal management of electronic devices using pin-fin based cascade microencapsulated PCM/expanded graphite composite. Int. J. Heat Mass Transf. 2020, 149, 119199. [CrossRef]

9. Ling, Y.Z.; Zhang, X.S.; Wang, F.; She, X.H. Performance study of phase change materials coupled with threedimensional oscillating heat pipes with different structures for electronic cooling. Renew. Energy 2020, 154, 636-649. [CrossRef]

10. Yang, X.H.; Tan, S.C.; He, Z.Z.; Liu, J. Finned heat pipe assisted low melting point metal PCM heat sink against extremely high power thermal shock. Energy Convers. Manag. 2018, 160, 467-476. [CrossRef]

11. Krishna, J.; Kishore, P.S.; Solomon, A.B. Heat pipe with nano enhanced-PCM for electronic cooling application. Exp. Therm. Fluid Sci. 2017, 81, 84-92. [CrossRef]

12. Yu, K.; Wang, Y.; Li, Y.X.; Baleta, J.; Wang, J.; Sundén, B. Effect of phase change materials on heat dissipation of a multiple heat source system. Open Phys. 2019, 17, 797-807. [CrossRef]

13. Zhao, J.T.; Qu, J.; Rao, Z.H. Thermal characteristic and analysis of closed loop oscillation heat pipe/phase change material (CLOHP/PCM) coupling module with different working media. Int. J. Heat Mass Transf. 2018, 126, 257-266. [CrossRef]

(C) 2020 by the authors. Licensee MDPI, Basel, Switzerland. This article is an open access article distributed under the terms and conditions of the Creative Commons Attribution (CC BY) license (http://creativecommons.org/licenses/by/4.0/). 